\title{
Algunos retos a la educación superior universitaria: enseñar a nuevas generaciones ¿'millennials' y 'centennials'?
}

\section{Some challenges to higher university education: teaching new generations ¿millennials' and 'centennials'?}

Las instituciones de educación superior están siendo interpeladas con interrogantes que se instalan como debates que necesitan urgente abordaje. Desconocerlos solo aceleraría la espiral de incertidumbre y de visión de una universidad que no está tomando nota de las demandas actuales a distintos niveles - macro y micro. Uno de esos interrogantes tiene que ver con el ingreso y permanencia del alumnado y las características de ese grupo. Es bien conocido por todos que en un porcentaje del 30 al $50 \%$ de los alumnos/as que ingresan a primer año abandona o se retrasa considerablemente entre primero y segundo año. ¿Causas? Podríamos abrir una inagotable lista de causas y enunciarlas. La literatura que circula sobre el tema distingue dos grandes problemáticas a tratar: preguntarnos cómo enseñamos (centra el debate en la formación del docente) y preguntarnos cómo aprenden esas nuevas generaciones que habitan las aulas. Ambas deben ser consideradas como temáticas indispensables. Lo cierto es que hoy circulan por las aulas universitarias personas que en su gran mayoría pertenecen a la llamada generación Y o "millennials" y estudios más recientes ya nos advierten de la incorporación en breve de la generación “centennials”. Los primeros nacieron entre 1982 y el 2000 y se estima que serán más del $70 \%$ de la fuerza laboral mundial en pocos años. Los segundos, están cursando estudios primarios, secundarios y los más antiguos quizás a punto de iniciar su vida universitaria.

Los Millennials son el producto de una generación cambiante, que puso en alto el valor del consumismo, el "tener" ante todo, marcado por el acelerado desarrollo de las nuevas tecnologías, en lo que nada es estático y todo debe cambiar. Les cuesta adaptarse a esquemas de organización vertical, estructuras rígidas, horarios fijos, les preocupa el hoy y ahora. Son reacios a leer textos largos y reclaman con frecuencia justificación y significado de las tareas que se le encomiendan tanto en el estudio como en el trabajo - al contrario de generaciones anteriores donde el 'sentido por el deber' no admitía cuestionamientos a la autoridad-. (Twenge, 2009) Los Centennials están ingresando a la vida universitaria en breve, comparten muchas de las características que se les señala a los Millennials, pero es la generación que tendrá el mayor acceso a la información y al conocimiento que todas las anteriores. Poseen una inmersión total al mundo digital, se ha establecido que pueden manejar 5 pantallas a la vez.

Revista Methodo: Investigación Aplicada a las Ciencias Biológicas. Facultad de Medicina. Universidad Católica de Córdoba. Jacinto Ríos 571 Bo Gral. Paz. X5004FXS. Córdoba. Argentina. Tel.: (54) 3514517299

/ Correo: methodo@ucc.edu.ar / Web: methodo.ucc.edu.ar | EDITORIAL Methodo 2020;5(1):2-3 
Es crucial entonces, que el claustro universitario tome nota de las características de estas nuevas generaciones que ingresan para poder ajustar la formación de estos nuevos profesionales aprovechando, por ejemplo, su manejo fluido de las tecnologías y su tendencia a adaptarse a los cambios; en general, son creativos, con facilidad para trabajar en equipos, pueden hacer varias cosas a la vez y nos reclaman objetivos claros y bajadas prácticas. De aquellos factores que traen una "disrupción” a lo que estábamos acostumbrados de las generaciones anteriores, como menor responsabilidad y compromiso, ausencias injustificadas, retraso en la atención, priorización de su tiempo libre, impaciencia, el "todo ya", se quiere una película, pues está al alcance de un dedo que presiono y ya... habremos también, de prestar especial atención.

El reto está en pensar nuevos modelos en educación, en cómo enseñar, qué competencias deben desarrollar los docentes y esos alumnos en el proceso de enseñanza aprendizaje, cómo abordar contenidos integrando disciplinas y herramientas digitales enfatizando un aprendizaje desde los casos problemas, sin desconocer la teoría, pero estableciendo un nexo dinámico con la práctica todo el tiempo. Es preciso actualizar estilos de enseñanza y valorar opciones de trabajo no tradicionales posibilitando y haciendo efectiva una mayor integración estudio- trabajo- vida. Se espera que esto contribuya al menos, a su inserción en la sociedad con responsabilidad a lo largo de la vida donde puedan alcanzar y desarrollar su máximo potencial.

En el área de las Ciencias de la Salud y en la formación de los médicos en general, cobra especial importancia este tema. Rescatamos a modo de cierre a un autor (Toohey SL, 2016) que brinda algunos consejos básicos en la disciplina que bien se pueden extender a otras, señalando la imperiosa necesidad de: cambiar los planes de estudios, incorporar instrucción interactiva individual en el sistema de aprendizaje, incorporar nuevos enfoques didácticos, atender a la eficacia de las conferencias, ( más breves y de alta calidad), incorporar un plan tecnológico coherente y usar la tecnología para una retroalimentación formativa eficaz, usar la simulación para optimizar los aprendizajes y la reforzar constantemente la relación teoría -práctica., entre otros.

Solo conociendo lo más acabadamente posible qué tipo de alumnado circula por nuestras instituciones, seremos capaces de desarrollar estrategias adecuadas que favorezcan una formación que supone redundará en profesionales no sólo con sólidos conocimientos y habilidades en su especialidad sino también en el desarrollo de actitudes y valores con capacidad a trabajar en equipo responsablemente en un contexto global cada vez más cambiante e incierto.

Esp. Olga C. Bonetti

Vicerrectora Académica Universidad Católica de Córdoba.

J.M. Twenge. The cross-cutting edge Generational changes and their impact in the classroom: teaching Generation. Med Educ 2009; 43: 398-405 http://dx.doi.org/10.1111/j.1365-923.2009.03310.x | Medline. http://doi.org/10.1111/j.13652923.2009.03310.x.

Toohey SL, Wray A, Wiechmann W, Lin M, Boysen-Osborn M. Moving an Emergency Medicine Residency Curriculum into the 21st Century West J of Emerg Med 2016; 17 (3): 337-343

Revista Methodo: Investigación Aplicada a las Ciencias Biológicas. Facultad de Medicina. Universidad Católica de Córdoba. Jacinto Ríos 571 Bo Gral. Paz. X5004FXS. Córdoba. Argentina. Tel.: (54) 3514517299 / Correo: methodo@ucc.edu.ar / Web: methodo.ucc.edu.ar | EDITORIAL Methodo 2020;5(1):2-3 